\title{
Some misconceptions or preconceived ideas on the history of the Insects
}

\author{
André $\mathrm{Nel}^{\mathrm{a}}$ \\ Institut de Systématique, Evolution, Biodiversité (ISYEB), UMR 7205 CNRS MNHN UPMC EPHE, \\ Muséum National d'Histoire Naturelle, Sorbonne Universités, CP. 50, 57 rue Cuvier, 75005 Paris, \\ France
}

\begin{abstract}
The Hexapoda is the most diverse clade of the history of life. They cannot be considered as the oldest terrestrial animals and the first Hexapoda were small apterous animals of the Devonian soil fauna, apparently not very diverse and "dominated" by myriapods and arachnids at that time. Things dramatically changed during the Early Carboniferous with the appearance and the expansion of the winged insects. This crucial innovation allowed this clade to diversify in a spectacular way in the Late Carboniferous. The main clades were already present at the end of this period, viz. Palaeoptera, "Polyneoptera", Paraneoptera and Holometabola. The latter two groups became truly diverse and began to dominate the animal kingdom after the major Permo-Triassic biodiversity crisis. Nevertheless a causal link is difficult to establish between the two phenomena. After the Triassic, all insect orders are present and many modern families are as old as the Jurassic, a situation completely different from that of the terrestrial vertebrates. The last major change in the hexapods took place about 100 Ma ago, and may be linked with the mid-Cretaceous angiosperm diversification, but apparently not with the supposed major crisis of diversity at the end of the Cretaceous.
\end{abstract}

\section{Introduction}

The Hexapoda (or six-legged arthropods) is the most diverse clade of animals, with more than one million species described and perhaps five to nine millions still awaiting description, representing over half of all described species. Numerous explanations have been proposed to explain this phenomenon, viz. their relative age, giving time for diversification to take place, supposed low extinction rates, flight or properties resulting from it like enhanced dispersal, wing folding, complete metamorphosis in the most diverse clades, small body size, and mouthpart diversity.

The tests of these hypotheses and consequent search for explanations of this phenomenon need joint phylogenetic analyses (using both molecular and morphological data) and a better knowledge of the fossil record. Our knowledge in both fields has greatly developed during the twenty last years, with the new tools in phylogeny (cladistics, maximum likelihood, Bayesian analyses) and the discoveries and studies of new, very rich and diverse fossil hexapod assemblages, especially in countries where

\footnotetext{
${ }^{a}$ Corresponding author: anel@mnhn.fr
}

This is an Open Access article distributed under the terms of the Creative Commons Attribution License 4.0, which permits unrestricted use, distribution, and reproduction in any medium, provided the original work is properly cited. 


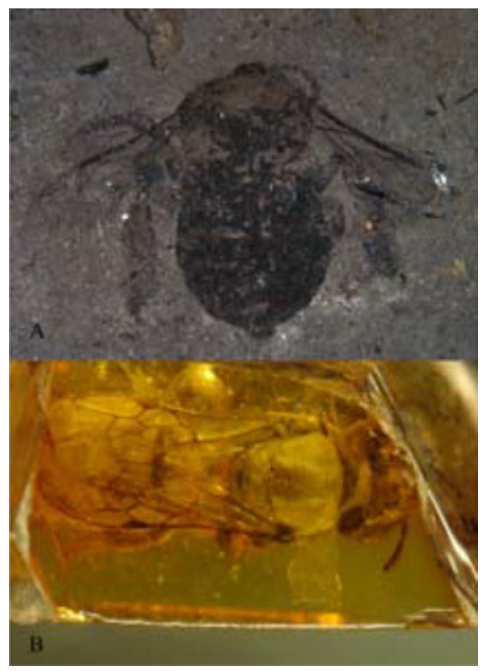

Figure 1. Bees fossilized as compression in lacustrine rocks (A) or embedded in amber (B). A. Paleohabropoda oudardi from the Palaeocene of Menat; B. Paleomacropis eocenicus from the Earliest Eocene amber of Oise.

these ancient organisms were previously unknown (Brazil, China, India, etc.) New gene sequencing technologies (genomics) have strongly increased molecular data and revolutionized phylogenetics. However molecular trees need fossil calibrations to be dated. New fossils or re-interpretations of the previously described taxa are more than ever necessary. But several preconceived negative ideas still affect the vision that neonatologists have of paleoentomology. We would like to discuss about some the most detrimental for any progress in the field.

\section{Are fossil insects very rare and useless for Science?}

Until the last twenty years, the hexapods had the bad reputation of fossilizing only in exceptional cases. Thus, these supposed very rare fossils were considered useless for the reconstruction of the history of this taxon. The situation has completely changed thanks to the increasing collaborations between the Russian, Chinese, American, and European searchers that occurred in the years 19982000. The discovery and study of very rich outcrops all over the World, dated from the Carboniferous to the Neogene have also changed dramatically the situation. If some crucial gaps remain in the fossil record, now the past entomofaunas and their evolution are well documented for the period from the Late Carboniferous to Recent.

Fossil insects can be found as compressions in lacustrine or fluviatile rocks, or included in fossil resins (ambers). Compressed fossils are generally preserved in two dimensions, which is not a real problem for the study of the wing venation but can render very difficult that of the body structures. Inclusions in amber have the great advantages of being three-dimensional and sometime exquisitely preserved, even with internal organs such as genital structures, now observable with the modern tools of the X-ray tomography.

But inclusions in fossil resins are generally small fossils due to the size of the amber pieces and to the facility with which large and powerful living insects can escape from fresh resin. Also, fossil resins with significant arthropod faunas are rather young (Early Cretaceous of Lebanon) compared to the antiquity of the Hexapoda (Devonian). On the contrary compressed fossils can be very large, and in some outcrops also exquisitely preserved with very delicate details (as is typical of the Middle Jurassic volcanic ash of Inner Mongolia, China). 


\section{ORIGINS}

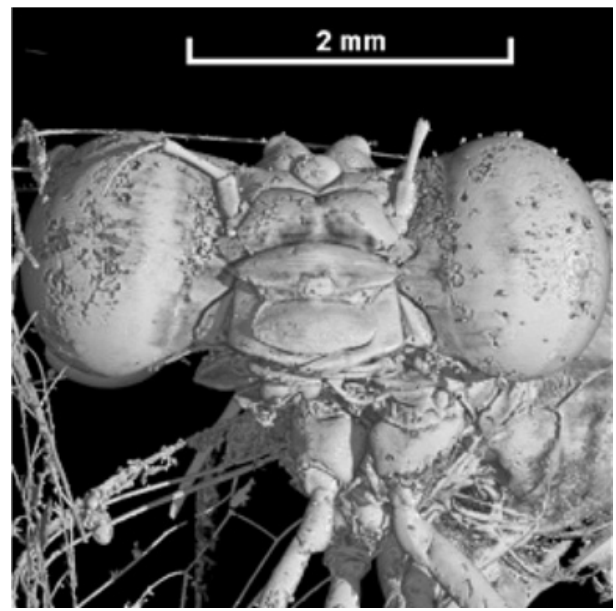

Figure 2. X-ray microtomography of the head of a small damselfly in Cenomanian (100 Ma ago) opaque amber of France.

Some fossil insects are preserved in more 'exotic' ways, included in selenite, salts, gypsum, cave stalactite, or sedimentary quartz. They can be three-dimensional replicas in silica, phosphate, or iron hydroxide (Cenozoic of Quercy, France; Early Cretaceous Crato Formation, Brazil).

Even some continental outcrops that were supposed to be azoic recently yielded a very rich entomofauna, as in the case of the red Permian of Lodève, France. Lastly, traces of activities (ichnofossils and plant attacks) can be of great help in some outcrops where the fossil animals are lacking.

For all these reasons, fossil insects are much more frequent than what was supposed twenty years ago. It is now possible to use them as direct witnesses of the hexapod evolution, to complete, date, and test phylogenies based on recent taxa.

\section{Did the insect diversity increase progressively from the Carboniferous to the Cenozoic?}

It is frequently supposed that the oldest winged insects were less diverse than those from the Mesozoic, especially after the diversification of the angiosperms that is supposed to have caused the major diversification of the insects.

The Devonian record of the Hexapoda remains very scarce [1]. The Hexapoda were clearly not a dominant clade in terms of diversity or abundance, even if it was already morphologically very disparate. These oldest Hexapoda were very small apterous animals of the soil fauna, eating organic remains. The first evidence of direct interactions between living plants and hexapods dates from the Carboniferous. If some very small Devonian coprolites have been found inside plants stems, they were probably caused by mites. There were no predators either among the Devonian hexapods, this role being filled by some Arachnida and Myriapoda.

The situation completely changed after the Early Carboniferous with an explosion of diversity that affected the winged insects, but not the apterous hexapod lineages. The wing was clearly a crucial innovation. The oldest known outcrops with Pterygota are dated from the Namurian of Germany, Czech Republic, and China. These localities provided very rich and diverse entomofaunas, with species belonging to extant taxa (cockroaches including the diverse Carboniferous Paoliida, Orthoptera or grasshoppers, Odonatoptera or dragonflies, etc.), but also other that correspond to extinct, strictly 


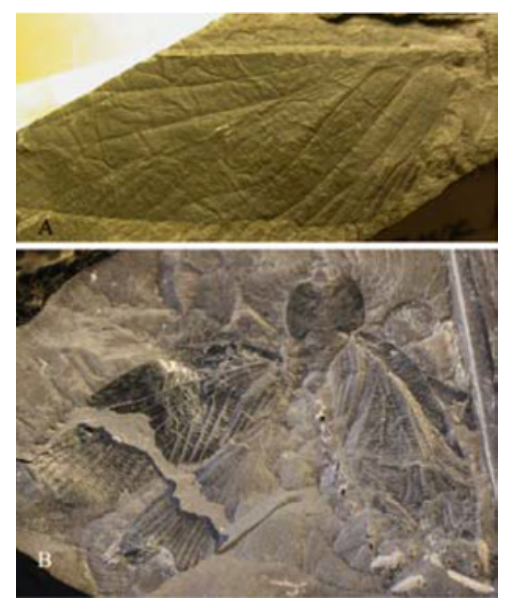

Figure 3. Representatives of various dictyopteran-like clades; A) The paoliid Paolia vetusta (Late Carboniferous); B) The dictyopteran Microblatta costalis (Late Carboniferous).

Palaeozoic groups, the most famous one being the Palaeodictyoptera [2]. Our knowledge on these earliest winged insects has greatly increased during these last years. These insect assemblages comprise taxa with a high morphological disparity corresponding to very different ecological niches, comprising detritivorous, herbivorous, and carnivorous insects. Interestingly the terrestrial plants seem to have diversified quite earlier than the phytophagous insects.

After the Namurian, insects began to greatly diversify, with the great majority of the known species being winged, while the apterygotan groups (and the other terrestrial arthropods) never diversifying in a comparable way. This diversification seems to be directly linked to flight, which allowed the exploitation of new ecological niches and a better capacity to survive, escape predators, colonize new places and new environments, etc. No gliding vertebrate appeared before the Middle Permian, and not flying ones till the Late Triassic; thus, winged insects were probably less vulnerable to predators than their wingless relatives. Consequently, the insects were probably the most diverse group of terrestrial organisms since the Late Carboniferous.

The fossil record suggests that the insects were already very diverse before $100 \mathrm{Ma}$. Since the Late Carboniferous, the rich insect Konservat-Lagerstatten have comparable diversity, with around 1000 insect species present in each locality. Thus, the apparent increase of insect diversity through time may simply be an artifact resulting from the increase in the number of outcrops in the most recent periods. Many of the older outcrops are hidden by more recent rocks or have disappeared because of erosion.

\section{Were the Carboniferous insects all giant?}

The image of the warm and wet Late Carboniferous green forests with giant arthropods is clearly false because the great majority of the Carboniferous insects are generally no larger than the recent ones. Some were very small (less than $4 \mathrm{~mm}$ long), even if they have been generally neglected by fossil collectors and have been collected only in these last few years [3].

The well-known (but poorly understood) gigantism of some Carboniferous-Permian insects may have been caused by an arms race between herbivorous and predatory insects, evolving gigantism; this process would not have been limited as it now is, because of flying vertebrate predators. It has been supposed that the higher concentration of atmospheric oxygen during the Late Carboniferous favored 


\section{ORIGINS}

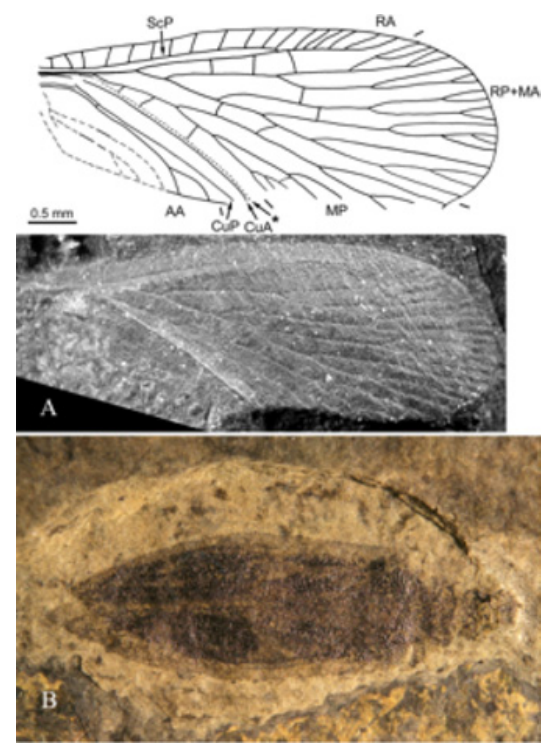

Figure 4. Oldest holometabolous insects. A) Westphalomerope maryvonneae, Early Late Carboniferous, North of France, drawing and photograph of hind wing; B) Oldest beetle, Latest Carboniferous of Germany.

the development of giant insects (the emblematic one being the griffenfly Meganeura monyi). But if these giants had very large wings, their bodies were not so large, being only as large as the largest modern beetles or stick insects [4]. Some of these "giants" were still present in the Middle Permian, when the partial pressure of oxygen began to decrease.

\section{The holometaboly: A crucial innovation, but with delayed consequences}

The most diverse animal clade is the Holometabola (Hymenoptera, Coleoptera, neuropteroid orders, Amphismenoptera, and mecopteroid orders), with nearly $85 \%$ of all insect taxa. Its monophyly is strongly supported by morphological and molecular data. The main set of morphological characters of the Holometabola concerns their specialized immature form, generally a slender, soft-bodied insect with three short pairs of thoracic legs or none, and no external wing buds. The immature form is usually considered one of the two most important innovations of insects, along with wings.

The fossil record shows now that the holometabolous insects were already present during the early Late Carboniferous with representatives of the mecopteran, hymenopteran, and coleopteran clades [3].

During the Permian, the fossil record of the Holomebola comprises "Mecoptera", Neuroptera, and Coleoptera. While the Coleoptera is the most diverse clade in all the outcrops with insects after the Middle Triassic, this taxon is rare in the Permian palaeobiota, and even absent in some of them ("red" Permian of Lodève, France). The Permian beetles were not adapted to all kinds of environments, unlike to Mesozoic and more recent ones. It seems that the innovation of the holometabolan larva was not sufficient to give a crucial advantage to allow an important Palaeozoic diversification of the clade. This diversification clearly took place during the Triassic, after the extinction of several other clades (especially the Palaeodictyopteroidea) at the end of the Permian. It seems that the holometaboly was not such a crucial "advantage", sufficient for a major diversification of these insects during the Late Carboniferous and Permian. 


\section{During the two major Permo-Triassic and Cretaceous-Cenozoic Crises, $\mathbf{8 0} \%$ of animals became extinct?}

These two crises are thought to be major events that have greatly affected the terrestrial life and the ecosystems. If this is true for the Vertebrates, it is far from being clear for the Hexapoda. A crisis is supposed to be a rapid event (a few thousand years) that affects abruptly the majority of living organisms. There is a first difficulty with the Permo-Triassic crisis and the Hexapoda: the world fossil record of this taxon is far from being well documented from five Ma before to five Ma after the event. Thus, it is difficult, if not impossible, to establish the exact timing of the extinctions that occurred around the alleged event. Second, if several Permian groups of insects are not recorded in the Triassic (the most emblematic one being the Palaeodictyoptera), many other taxa survive through the boundary without apparent problems. Also, some of the orders that were supposed to disappear at the end of the Permian are in fact paraphyletic and have descents in the Triassic (such as the emblematic case of the "Protorthoptera").

The impact of the Cretaceous-Cenozoic (K-T) crisis on insects should be better documented because the fossil record is better for these more recent periods, and because these fossil insects are known not only in lacustrine rocks, but also in amber. It is clear that no insect order became extinct at the K-T boundary, and nearly all the Cretaceous families go through the boundary, and several become extinct during the Paleocene (as is the case of some Mesozoic chrysopid-like forms that are still present in the Paleocene of Denmark). However important changes in arthropod traces of activities on plants at the K-T boundary have been documented, supporting an impact of the crisis on insects. The current scenario for this crisis implies very unfavorable conditions of life world-wide, even for the insects, with dark and cold conditions during several months, if not years. This is incoherent with the persistence of nearly all insect families that were present during the Late Cretaceous. However, what we call an insect family is generally a large clade that can comprise hundreds or thousands of species, some of them being more generalist and less sensitive to environmental changes than the others. In consequence, a major crisis could have greatly affected many, but not all of these species, so that the family itself could survive and re-diversify after the crisis. In other words, the family Tyrannosauridae with its six genera is more vulnerable to extinction than the Chalcidiidae with thousands of genera. Unfortunately, it is still impossible to estimate the impact of the Permo-Triassic or Cretaceous-Cenozoic crises at the species level for the Hexapoda because there are still not enough described fossil insects for the different periods, even if thousands of fossils await description. But after all, after $65 \mathrm{Ma}$, what are important are that all the insect families and thus all their trophic relationships with their environments survived the K-T boundary and persist today.

The two major crises of biodiversity maybe never happened in the sense that their impacts on the major clade of terrestrial organisms are still poorly understood.

\section{What about the 100 Ma revolution of insects?}

After the Early Carboniferous development of the wings and the probably rapid diversification of the greatest pterygote clades (Paleoptera, polyneopteran orders, Paraneoptera, and Holometabola), the second major event in insect history took place relatively recently, around $100 \mathrm{Ma}$ Ago (around the Albian/Cenomanian boundary, which is also the boundary between Early and Late Cretaceous), in response to the diversification of the flowering plants. The insects that feed on angiosperm flowers diversified (moths) or appeared (bees) then. The oldest records of the great majority of the extant insect families go back to this time or a little earlier in the Early Cretaceous Lebanese amber. 


\section{ORIGINS}

\section{References}

[1] R. Garrouste, G. Clément, P. Nel, M. S. Engel, P. Grandcolas, C. D’Haese, L. Lagebro, J. Denayer, P. Gueriau, P. Lafaite, S. Olive, C. Prestianni, A. Nel, Nature 488, 82-85 (2012)

[2] D. A. Grimaldi, M. S. Engel, Evolution of the insects (Cambridge University Press, 2005)

[3] A. Nel, P. Roques, P. Nel, A. A. Prokin, T. Bourgoin, J. Prokop, J. Szwedo, D. Azar, L. DesutterGrandcolas, T. Wappler, R. Garrouste, D. Coty, D. Huang, M. Engel, A. G. Kirejtshuk, Nature, 503, 257-261 (2013)

[4] A. Nel, G. Fleck, R. Garrouste, G. Gand, J. Lapeyrie, S.M. Bybee, J. Prokop, Palaeontographica (A), 289, 89-121 (2009) 